\title{
PERSPECTIVE DIRECTIONS OF INNOVATIVE MANAGEMENT IN THE CONDITIONS OF THE RUSSIAN ECONOMY
}

\author{
NATALIA GOLUBETSKAYA \\ Saint Petersburg state university of economics and finance, Russia
}

\section{ABSTRACT}

Innovative development of economy is a necessary condition for increase of competitiveness of Russia. Organization change should pass consistently taking into account a strategic target of development of the Russian economy as a whole. The analysis of work of the large innovatively focused corporations has shown that an important direction of formation of system of innovative activity in Russia is development of interaction, integration of large, small enterprise structures and educational institutions. Stopping development threatens the organization with the stagnation, therefore each organization needs to develop strategy plans for development directed on formation of competitive advantages. The author analyzes advantages of strategy creation, the criteria necessary at an estimation of projects within the limits of innovative programs which differ depending on specificity of organizational structure, a skill level of the personnel and efficiency of production as a whole.

\section{JEL CLASSIFICATION \& KEYWORDS}

- $\mathrm{O} 3$ - Innovations - Management a Stable development of organization

\section{INTRODUCTION}

Key tendencies of development of the modern world connect with transition to the economy which is based on intensive integration of knowledge (knowledge based economy). Dynamics of economic indicators of the industrial countries shows that the innovative way of social development becomes the basic precondition of economic growth and economy modernization. "Lisbon Strategy» of development of knowledge economy became considerable achievement of a world innovative policy, accepted by the European Union, for policy improvement in the sphere of education, scientific researches and venture business, creation of a favorable innovative climate and development of information technology. The innovative economy is an uncontested way of development for Russia if as strategy of development of the state to consider increase of competitiveness of national economy.

\section{Formation of innovation activity in Russia}

The analysis of work of the large innovatively focused corporations has shown that an important direction of formation of system of innovative activity in Russia is development of interaction, integration of large, small enterprise structures and educational institutions. This complete system allows: a) to increase the offer of innovations on qualitatively new scientific basis and demand for them in industrial sphere; $b$ ) to strengthen integration of a science, education, manufacture and the market; c) process of a birth and development of innovative firms to facilitate essential, raising their economic stability; d) to expand financial possibilities of the innovative enterprises at the expense of access to bank credits; e) to save time and means of large corporations on research and developmental works and on reorganization of technological production programs, on development of a diversification of own manufacture.
Stoppage of development threatens to organization with stagnation, and loss of competitiveness and market positions at dynamical, constantly changing and an emerging market. Therefore in plans for development of any organization programs of the further development should be provided and developed.

Occurrence of a change can be traced based on the chart (fig.1):

\begin{tabular}{|c|}
\hline Figure 1: Stages of organization competitive advantages creation \\
\hline Organization economy \\
Manifests itself through \\
Economic figures \\
\hline $\begin{array}{c}\text { They are used to adjust } \\
\text { Economic programs and plans of educational services } \\
\text { control }\end{array}$ \\
\hline Which cause \\
\hline Changes in the economic system \\
\hline Market position and public recognition of an \\
organization
\end{tabular}

Changes play a main role as the processes improving activity of the enterprise during of the organization development. With growth of a science role and technics as factor of development of economy there is a necessity of management of these processes. It is possible to speak about possibility and dependence of managerial process on reform of the organization, characterized by the variability at realization of strategy of development or functioning of economic system $[1,5]$. Actions for complex management of organizational and corporate components are necessary for management of changes in the organization in the first case for what it is necessary to generate a subsystem of management of changes.

In this case it is possible to optimize the function of an economic system (fig.2) (Cobb-Douglas PF or CES) $\left(Y=A{ }^{*} K^{\alpha 1} O^{\alpha 2}\right)$

In an opposite case the organization doesn't increase activity and doesn't develop, and actually, it comes to cyclic functioning. Organization criterion function in outside sphere is balanced.

Function of linear dependence is possible on the condition of permanent performance efficiency (fig.3).

Efficiency of changes in the organization comes to naught because of management loss at occurrence of irrepressible conflict (fig.4) (Leontiev f.).

All production functions of organizational changes can be generalized. The most known generalization is CES function, - a function of constant elasticity of substitution.

Linear function has zero "curvature" and accordingly, infinite elasticity of replacement $h$ (an indicator simple system functioning). Cobb-Douglas function has elasticity of 

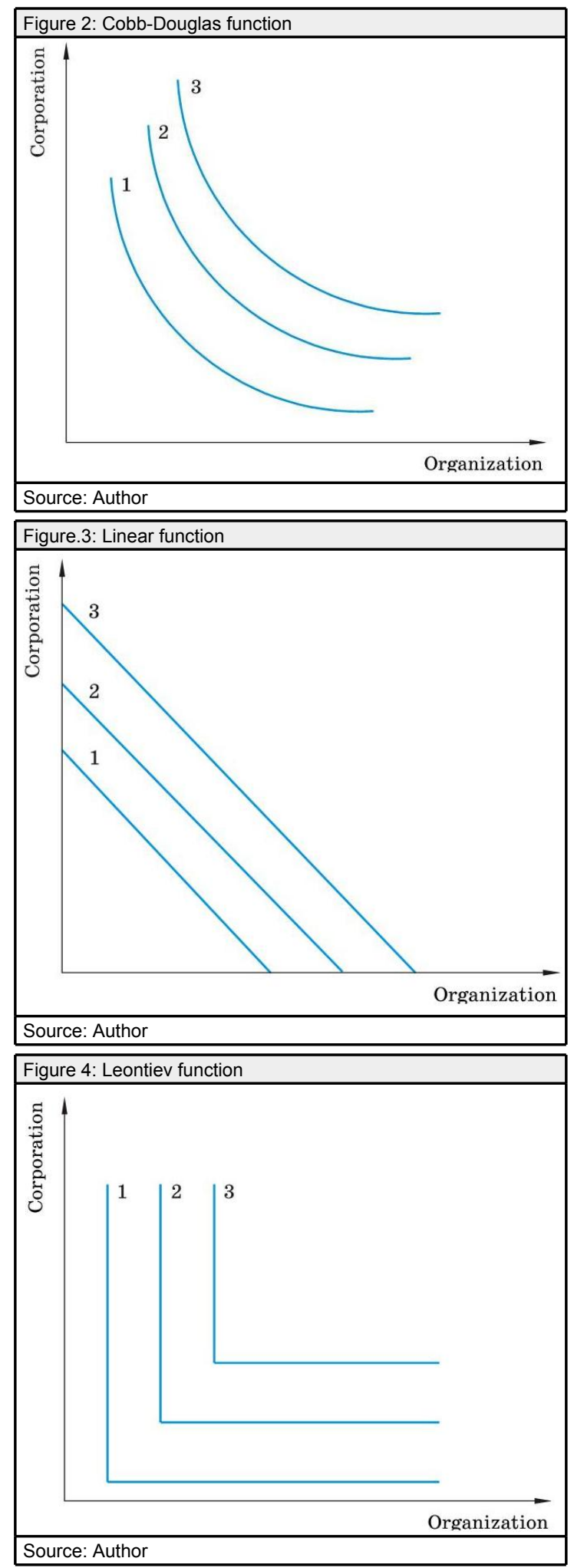

substitution equal to one (an indicator of system development) [4]. Leontiev function has zero elasticity of substitution (organizational and corporate elements in it remain on the fixed positions and don't make a compromise). In a reality interchangeability degree can be various, www.journals.cz/ according to various (and not just zero, infinite or individual) and can be elasticity of replacement. It puts a problem of estimation more the general formulas PF, in particular PF from a constant, but any elasticity of replacement. Such function (function CES) (fig. 5) is described by the formula: $Y=A\left(u K-p+(1-u) O^{-p}\right)^{-n / p}$

Where $\mathrm{p} \geq-1 ; \mathrm{n}>0-$ degree of homogeneity; $\mathrm{A}>0$, $0<u>1$. Elasticity of substitution for such function equals $\frac{1}{1}+p$. If $p=-1$, we receive a function with linear isoquant curves (particularly, a linear function), if $p \rightarrow 1$, in extreme case we get Cobb-Douglas PF with $h=1$, if $p \rightarrow \infty$ - Leontiev PF.

CES function is widely applied in macro- and microeconomics. Such assessments have been made by E.B.Ershov, Y.V.Yaryomenko and A.S.Smyshlyaev, M.Veitsman, A.G.Granberg, N.B.Barkalov and others [2].

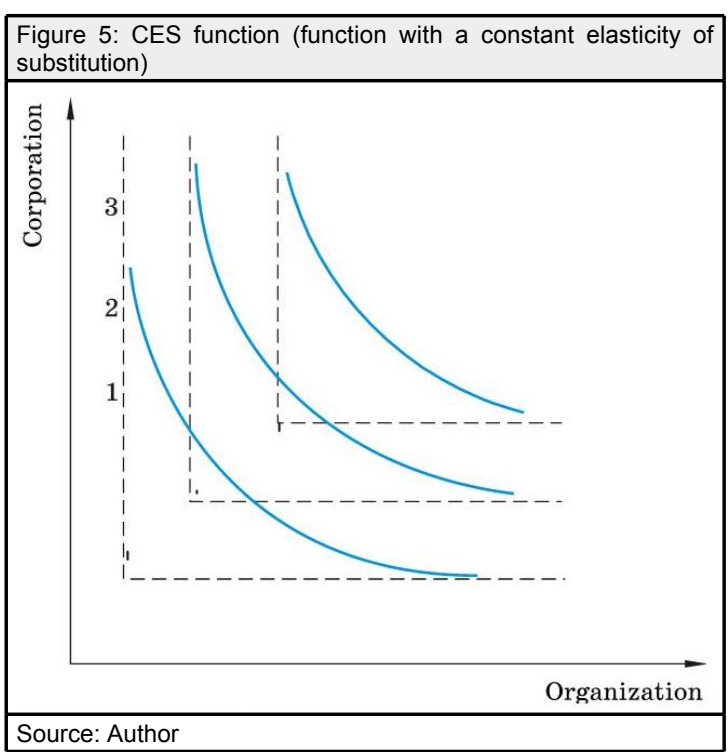

It is not found yet adequate model or technology of management by changes both at organization level, and at state level. At the same time practical realization of scientific and technical and social results for a long time already became a primary factor of social development and growth of competitiveness of the enterprise in market economy.

It is necessary to recognize that management of changes will be under construction on a flexible combination egressive, coalition and cooperative principles of construction of organizational structures (fig. 6).

Figure 6: Combination of egression, cooperation and coalition in organization change management

Change management in an organization

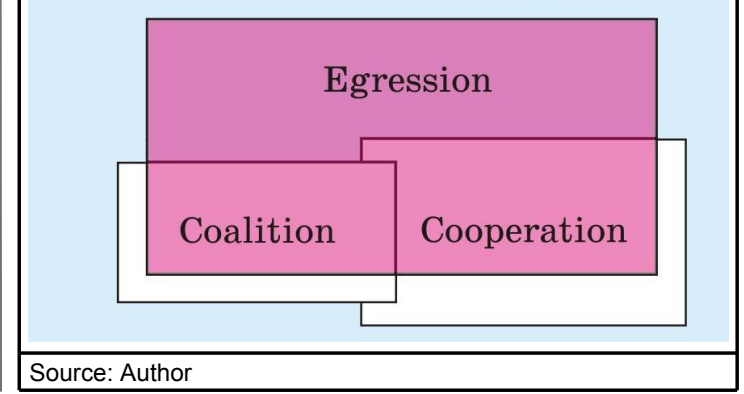


Example of egressive as organization forms - administrative and command system, a strict subordination and hierarchy of submission. A coalition example - a commission of experts which is carrying out generating of ideas. In this mode councils of all levels work. A cooperation example temporary creative collective. So any organizations can work within the limits of target programs on realization of changes. The mechanism of management should be developed for successful realization of changes by the changes, adequate to modern techniques and new technologies.

The mechanism is understood as set of conditions and processes of which there is any phenomenon [3], thus the system of communications, restrictions, the links inducing object to change in a desirable direction is necessary for definition and management of the given set or to operate definitely. Known "non-material" mechanisms it is possible to arrange on degree of increase of their complexity. If the divergence between a vector of natural changes of object and a direction of desirable changes is very great, it conducts as to mechanism complication, and growth of its "capacity" (fig. 7, 8).

The example illustrating this statement, comparison of degree of satisfaction of public requirements (quantitative and qualitative) by means of an adjustable market mechanism and the mechanism of the centralized directive planning can serve. It is possible to conclude that mechanism use in any sphere is attempt of the permission of the private contradiction between object conditions. In educational sphere changes in the organization the subject of management achieves object transition in a desirable condition by creation.

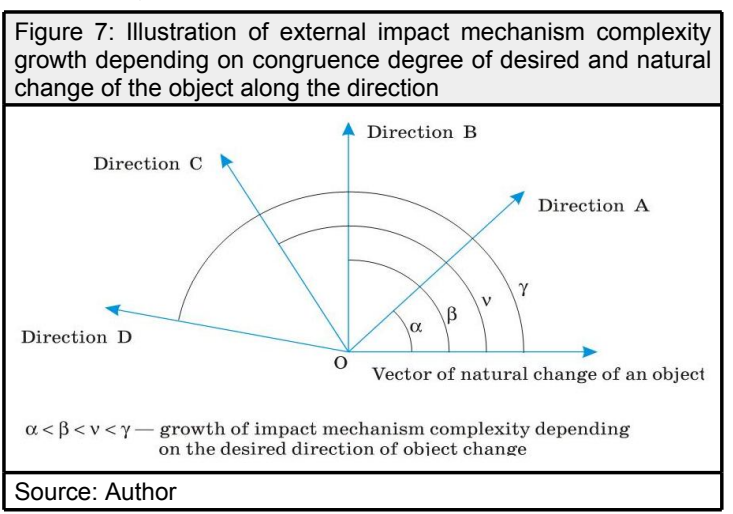

Figure 8: Illustration of external mechanism of impact power increase

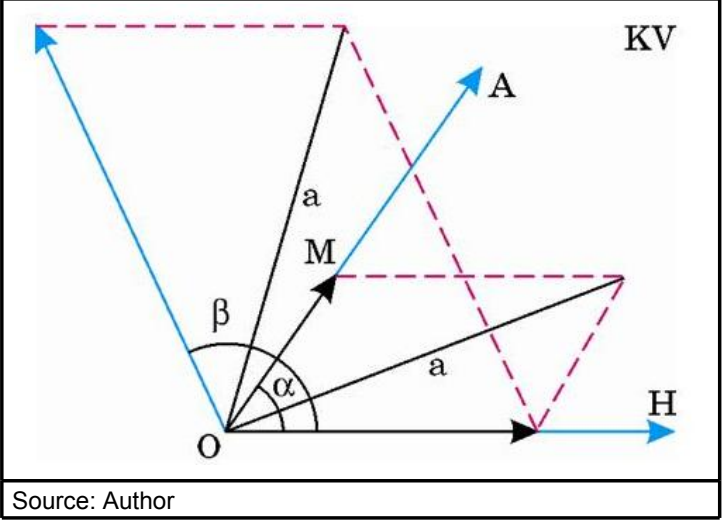

In educational sphere a management subject makes the object to transit to a certain state through creation of www.journals.cz/ mechanism of such a transition and provision of continuous working of the mechanism (fig.9).

Figure 9: Change of the state of the object under control

Transition through implementation of

State A-1-onsition through implementation of
external mechanism

Source: Author

Thus, the mechanism of changes is system of models and methods, the imperative and indicative regulations making methods of management by practical realization of organizational changes (innovations) of the organization [3]. Finally the problem of management of changes consists in correctly to estimate an essence of the processes occurring in external and internal spheres of a higher educational institution and its structural divisions, to select and introduce those innovations which will reduce all variety of influences to a uniform line of conduct, to raise efficiency of activity of the organization.

\section{Concept and model of the term "organization"}

The concept «organization» in a modern science is one of the fundamental. In its maintenance is concluded three aspects: attributive, subject and functional [4]. In attributive aspect the organization can be characterized as set of signs of concrete system.

In subject aspect concept "organization» means the independent group of the people focused on achievement of a definite purpose coordinated in actions. In functional aspect the organization can be considered as set of labor technological processes and the actions directed on means and objects of the labor for reception of required effect.

The concept of the organization as process includes following elements:

1. Objective, tasks.

2. Tasks grouping for definition of work types.

3. Work types grouping in the corresponding subdivisions.

4. Delegation of authorities, allocation of responsibilities and identification of number of levels in management hierarchy.

5. Creation of organizational climate, which promotes the employees to make maximum contribution to the achievement of company objectives.

6. Design of communication system which provides efficient decision-making, control and coordination.

7. Creation of organizational system which provides internal coordination of all the elements of organization, responsiveness to the changes of the external sphere and capability to adapt to it.

From the historical point of view classical model of the organization is the is administrative-bureaucratic model of the scientific organization of educational process which in many respects has behavioristic source and is based on the approach of reducing. The economic component includes rational use of resources for achievement of economic targets with the least expenses in minimum possible terms [2]. Methodological approach to formation of the organizational mechanism of management by changes in economic system includes the following maintenance:

- Selection of strategy of organizational changes,

- definition of principles of organizational mechanism creation, 
- development of object-oriented integral program of organizational changes,

- definition of a function of organizational mechanism,

- definition of mechanism and change management elements' structure,

- selection of technology, models and methods of program implementation,

- calculation of necessary resources for implementation of organization change program,

- implementation of organization change program,

- control of the final results.

The choice of strategy of management of changes directly depends on life cycle of the enterprise and connected with it the condition of the enterprise at various stages of the development (table 1). According to the existing practices, the development of strategy is usually follows a phase of organizational development, in which frameworks measures are taken to improve a state of affairs in the organization and to raise its competitiveness and readiness for the further development [1]. Choice of strategy is carried out by the organization depending on role and substantial function of an innovation.

\begin{tabular}{|c|c|c|}
\hline \multicolumn{3}{|c|}{$\begin{array}{l}\text { Table 1: Behaviour of an organization on different stages of its } \\
\text { development }\end{array}$} \\
\hline & \multicolumn{2}{|c|}{$\begin{array}{l}\text { Behaviour of an organization on different } \\
\text { development stages }\end{array}$} \\
\hline \multirow{9}{*}{$\begin{array}{l}\text { Stages of } \\
\text { business } \\
\text { development }\end{array}$} & \multirow{3}{*}{$\begin{array}{l}\text { expansion of } \\
\text { the existing } \\
\text { business }\end{array}$} & $\begin{array}{l}\text { Investments in the educational } \\
\text { activity }\end{array}$ \\
\hline & & Production of new services \\
\hline & & Cutting off competitors \\
\hline & \multirow{3}{*}{$\begin{array}{l}\text { development } \\
\text { of a new } \\
\text { business }\end{array}$} & Investments in new directions \\
\hline & & Imitation and adjustment \\
\hline & & Exclusion of competitors \\
\hline & \multirow[t]{2}{*}{ stabilization } & Scientific and research activity \\
\hline & & $\begin{array}{l}\text { Provision of competitiveness } \\
\text { which guarantees the market } \\
\text { share }\end{array}$ \\
\hline & rolling-up & $\begin{array}{l}\text { Support of regular activity without } \\
\text { investments in physical assets } \\
\text { growth }\end{array}$ \\
\hline
\end{tabular}

In the course of strategy working out the coordination as starting positions, and received results is carried out. According to it the development general plan in which the major factors defining process of transformations are formulated is developed. They are subdivided into external factors (for example, changes in the legislation, including in educational activity) and internal (orientation to profit, development of business skills at all levels of the organization, etc.).

Considering new ideas, theories, goals of global community development, the new approaches and new principles should change the functions of management in the educational sphere [3], management principles should transform also. Change management principles are determined by the objectives and strategy of organization, as well as by a number of factors - scientific and research, economic, social and political factors. The following organization management principles which target at its sustainable development can be identified.

1. Considering requirements. Increase of value of educational services for the consumer - overall objective of a higher educational institution. It means elimination of those kinds of activity which the purposes of perfection of an end-product don't serve. All kinds of activity are focused on constant improvement of quality of educational service.

2. Accuracy. Strict discipline - all promises and obligations between structural divisions of the organization and consumers are firm.

3. Reliability. Simplicity of the organization and a direction of information streams, optimization of work of all services and divisions, elimination of sources of uncertainty of work of structural divisions. The main task to have necessary materials and the information in a proper place and in due time.

It is a question not about of time changes, it is about formation of base for constant improvements. Following these principles, the enterprise is able solve a problem of increase of efficiency of educational activity with the minimum resources. Almost all elements, functions, technologies and structures of a higher educational institution should undergo essential changes. [1]The undertaken efforts will appear effective only if such important stages of organizational changes as won't be missed:

- Creation of positive emotional background of the current changes,

- creation of public support of change - to involve reputable and positive employees,

- create control and results analysis system - support confidence of people: goals can be accomplished,

- provision of information - arrange regular feedback on the progress of change, inform about success,

- implementation of not only material, but also symbolical changes - create new mentality,

- focus on processes - be ready to re-build businessprocesses if it is necessary.

Stoppage of development threatens to organization with stagnation, and loss of competitiveness and market positions at dynamical, constantly changing and an emerging market. Therefore in plans for development of any organization programs of the further development should be provided and developed.

Program structure includes the following blocks:

I. Target.

The overall objective is fixed in it, its decomposition with reference to executors is made, the sequence and terms of their realization, system of indicators of their work is defined.

II. Technical and economic.

Includes a set of measures and solutions, related to the realization of changes and their practical implementation, maintenance of the economic figures of the department in the compliance with the requirements of the academy, development of academic teaching methodology for the disciplines of the department of management.

III. Block of program resources' provision.

In this block working out of all kinds of maintenance is planned: legal, financial, personnel, information, organization, etc. The greatest difficulties arise in connection with weak training for changes of the personnel and level of financing of stages of performance of the program.

IV. Organizational block.

Determines the structure of the executors and the order of their interaction during implementation of measures, their rights and responsibilities, i.e. organizational system. 
V. Efficiency of program implementation.

As the program of modernization of educational process has accurately expressed innovative character, efficiency indicators characterize:

- Development of the economic system,

- introduction of scientific management methods by changes,

- creation of conditions for integration of academy into the European educational process,

- perfection and creation of system of an effective estimation of productivity of educational process and quality of professional work of teachers.

\section{Conclusion}

It is important that practical achievements and possibilities of a wide circulation of experience of the advanced chairs should be carried to effects of the program of modernization of educational activity.

It is possible to recommend formation of a time subsystem of management by innovations of matrix type for all innovative actions in sphere of educational services. On a vertical administration of resource maintenance of the program actions included in the plan of activity is exercised. Administration of programs of heads of programs is across exercised. In the conditions of changes matrix structures of management are one of the major factors of efficiency and efficiency of use of resources and that is rather essential, effective control behind target use of these resources by increase of responsibility of the head for performance of innovative educational programs [5]. Criteria necessary at an estimation of projects within the limits of innovative programs, differ depending on specificity of organizational structure, a skill level of the personnel and efficiency of production as a whole.

\section{REFERENCES}

1. Gnevko V.A. Modernization of model and technologies of specialists' training in Russian IHLs. // Economics and management. № 10 (60) 2010, p.16 -19.

2. Gusakov M.A. Role of Saint-Petersburg in science and innovations development.// Economics and management. № 10 (60) 2010, p.34 -36 .

3. Golubetskaya N.P. Development perspectives of innovation management based on the regional system of innovation activity.// Present day management: problems and perspectives. 2010, p.410 $-412$.

4. Golubetskaya N.P. Innovation management as a mechanism of companies' competitiveness and investment potential growth.// Strategy of innovative development of North-West regions of Russia: experience and problems., SPbAME, 2009, p.75 - 78.

5. Golubetskaya N.P. and others. Innovation management of logistics systems. SPbAME, 2010, p.185- 200.

6. Kovalenko B. Methodological features of modern institutional economics.//Social and natural sciences journal,2011, p. 55-61 